\title{
UN DOCUMENTO INÉDITO DEL SIGLO XVIII. EL PADRE JESUITA PEDRO LOZANO Y SU PRIMERA CARTA ANUA, 1720-1730
}

POR

\author{
Pedro Miguel Omar Svriz Wucherer \\ Instituto de Investigaciones Geohistóricas-CONICET (Argentina) \\ Facultad de Humanidades-UNNE (Argentina)
}

\section{RESUMEN}

Las Cartas Anuas de la Provincia Jesuítica del Paraguay son fuentes históricas muy importantes e indispensables para la reconstrucción de la labor cultural y evangelizadora realizada por la Compañía de Jesús en los territorios del Río de la Plata. Por esta razón, la edición y análisis de este tipo de fuentes son tareas fundamentales, en este caso nos referiremos a la primera Carta Anua que realizó el padre Lozano y que informan al padre General, residente en Roma, acerca del contexto en los cuales desarrollaron su labor evangelizadora los padres de la orden. Además resaltaremos la figura de su autor el padre Pedro Lozano, el contexto en el cual escribió, la función que cumplieron estos documentos, y algunas de las particularidades y tópicos que expone esta fuente de la primera mitad del siglo XVIII.

Palabras Clave: Pedro Lozano, siglo xviII, Río de la Plata, Cartas Anuas

\section{AN UNPUBLISHED DOCUMENT OF THE EIGHTEENTH CENTURY. PEDRO LOZANO JESUIT FATHER AND HIS FIRST LETTER ANUA, 1720-1730}

\begin{abstract}
Letters Anuas of the Jesuit Province of Paraguay are very important and historical sources necessary for the reconstruction of the cultural and evangelizing by the Company of Jesus in the territories of the River Plate. For this reason, the editing and analysis of such sources are fundamental tasks in this case we refer to the first letter Anua made by father Lozano and reporting to the father General,
\end{abstract}


resident in Rome, about the context in which they developed their evangelizing work parents of the order. Besides highlighting the image of the author, father Pedro Lozano, the context in which he wrote, the role of these documents, and some of the particularities and topics that exposes the source of the first half of the eighteenth century.

KEY WORDS: Pedro Lozano, eighteenth century, River Plate, Letters Anuas

Recibido/Received 22-09-2009

Aceptado/Accepted 18-01-2012

El presente trabajo tiene como eje fundamental el análisis de un documento inédito del siglo XVIII al cual consideramos de gran importancia para un abordaje pormenorizado del contexto que atraviesan los territorios rioplatenses durante el periodo $1720-1730$.

Por lo cual comenzaremos nuestro estudio teniendo como punto de partida tres interrogantes claves, como ser: ¿Quién escribe el documento? ¿Cuándo lo escribió al mismo? Y finalmente ¿por qué se lo escribió? Si bien estas preguntas son muy simples y obvias, constituyen el punto de partida indispensable y obligatorio para todo historiador ante un documento histórico. Por ello consideramos oportuno iniciar nuestro trabajo esbozando respuestas para cada uno de estos interrogantes y, posteriormente, nos abocaremos al valioso relato de estas Cartas Anuas.

\section{El autor de esta inédita Carta anua: el Padre Pedro Lozano}

Pedro Lozano redactó las Cartas Anuas de la Provincia Jesuítica del Paraguay en el periodo 1720-1730. Su biografía debe ser expuesta a fin de entender quién fue el autor del documento.

Lozano nació el 16 de junio de 1697 en Madrid, España; siendo admitido con sólo 15 años en la Compañía de Jesús, 26 de junio de 1712. Luego de dos años fue trasladado al Nuevo Mundo, llegando al puerto de Buenos Aires en julio de $1714^{1}$ luego de tres meses de navegación y junto a otros setenta y dos misioneros.

\footnotetext{
${ }^{1}$ Con respecto a esta fecha debemos decir que Guillermo Furlong menciona que otros autores, caso de Astrain y Storni, confundieron el año del ingreso a la Compañía para pasar al Paraguay (1712) con la fecha en que efectivamente pasó a América Pedro Lozano (1714); dato importante que debemos considerar para evitar posibles confusiones sobre su vida. Véase Furlong, Guillermo. 1959. Pedro Lozano S. J. y sus «Observaciones a Vargas» (1750): 11 Buenos Aires, Librería del Plata 1959.
} 
Entre ellos nos dice Guillermo Furlong no sólo hubo españoles, italianos y alemanes, demostrando la vigencia de la llamada «internacionalidad» de la Compañía; sino también hombres tan insignes como Aperger, Nusdorffer, Lizardi, Klausner y Pallozi. Pero ninguno adquirió con el correr de los años tan merecida fama como lo haría el joven Pedro Lozano, que por entonces contaba con sólo 17 años. ${ }^{2}$

En 1715, el joven Lozano llegó a la ciudad de Córdoba para realizar sus estudios en Filosofía (1716-1718) y luego en Sagrada Teología (1719-1723).

Paralelamente a su etapa de estudiante, a partir del año 1720, Pedro Lozano asumió la responsabilidad de redactar los informes regulares al General de la Compañía residente en Roma; las llamadas «Cartas Anuas». Al finalizar esta etapa, hallamos a Lozano en la ciudad de Santa Fe como profesor del colegio jesuita entre los años 1724 y $1730 .^{3}$

Hacia 1730 Lozano profesó su cuarto voto en Córdoba. En ese año también se estableció en dicha ciudad, dato muy importante dado que a partir de esta fecha aparece en todos los catálogos de la orden con el título de Historiógrafo de la Provincia Jesuítica del Paraguay, cargo que ocupó hasta el ocaso de su vida.

$\mathrm{Su}$ traslado a esa ciudad fue la respuesta a la estima que los superiores jesuitas comenzaban a tener con el padre Lozano ${ }^{4}$ y la necesidad que estuviera más cerca de los fondos documentales, con los cuales ya comenzaba a delinear y escribir algunas de sus grandes obras.

Su dedicación a la historia fue algo poco habitual, como lo advierte Carlos Leonhardt en su obra:

«... sucedió con el padre Lozano una cosa casi inaudita en aquellos tiempos de vida misional: fue destinado por toda su vida restante, casi exclusivamente, a los trabajos de investigación histórica, figurando en los catálogos de la Orden con el título único de Historiador de la Compañía de Jesús». ${ }^{5}$

\footnotetext{
${ }^{2}$ Ibídem: 12.

${ }^{3}$ Precisamente en las Cartas Anuas que analizamos, Lozano describe de manera detallada la situación penosa y de crisis que vivió la ciudad de Santa Fe, por los constantes ataques de los indios abipones a lo largo de los diez años que abarcan estas cartas. Dicho grado de detalle se debe a que el propio Lozano afrontó esa situación, ya que durante ese periodo se desempeñó en el colegio de esa ciudad. Véase 2009. Cartas Anuas de la Provincia Jesuítica del Paraguay. 1720-1730, Resistencia, Instituto de Investigaciones Geohistóricas-CONICET 2009, f. 37vta.-f. 41. [En adelante CAPJP. 1720-1730]

${ }^{4}$ Recordemos que la capital, y por ende residencia del provincial de la Provincia Jesuítica del Paraguay era la ciudad de Córdoba; más adelante podrá observarse la magnitud de este colegio en comparación con los restantes ubicados en este territorio, lo cual permitirá hacernos una idea de la importancia de esta ciudad dentro de la organización de la Compañía de Jesús.

${ }^{5}$ Furlong, Guillermo. 1959: 19.
} 
Llegado a América para dedicar su vida a la labor evangelizadora de los indios de las reducciones, las dotes personales de Pedro Lozano hicieron que sus superiores le asignaran la tarea de escribir la historia de la Provincia Jesuítica del Paraguay. En este ocupadísimo ocio pasó los últimos veintiséis años de su vida, muriendo el 8 de febrero de 1752 en Humahuaca, Jujuy; a la edad de 55 años. ${ }^{6}$

$\mathrm{Su}$ legado escrito es extenso y muy rico. Se halla en distintos repositorios documentales, archivos y bibliotecas de Argentina, Brasil, Chile, España, Paraguay, Uruguay entre otros países. Este valioso legado está siendo objeto de la edición de algunas de sus inéditas obras. Este es el caso de las Cartas Anuas del período 1720-1730.

No es posible exponer cada uno de los numerosos títulos escritos de Lozano, dada su extensa y prolífica labor como escritor. ${ }^{7}$ Pero hay que mencionar algunas de sus obras por su relevancia histórica para todos los interesados en temas de historia colonial del Río de la Plata y, especialmente, para los que analizan el desempeño de la Compañía de Jesús en esos territorios:

- Descripción Chorographica del terreno, ríos y árboles, y animales de las delatadísimas Provincias del gran Chaco Gualamba; y de los ritos y costumbres de las innumerables naciones bárbaras e infieles, que la habitan; con una cabal relación histórica de lo que en ellas han obrado para conquistarlas algunos gobernadores y ministros reales; y de los misioneros jesuitas para reducirlas a la fe del verdadero Dios. Publicado en Córdoba (España) en el año $1733 .^{8}$

- Historia de la Compañía de Jesús en la Provincia del Paraguay. Publicada en Madrid, año de 1754.

- Historia de la Conquista del Paraguay, Río de la Plata y Tucumán. ${ }^{9}$

- Historia de las Revoluciones de la Provincia del Paraguay 1721-1735. Publicada en Buenos Aires en el año 1905.

\footnotetext{
${ }^{6}$ Una breve reseña de la vida del padre Lozano puede hallarse, además de la mencionada obra del padre Furlong, Guillermo. 1959, y en Storni, Hugo. 1980. Catálogo de los jesuitas de la provincia del Paraguay (Cuenca del Plata) 1585-1768: 167. Roma: Institutum Historicum S. I.

${ }^{7}$ En la citada obra de Guillermo FURLONG puede observarse un detallado listado de cada uno de los escritos del padre Lozano, con comentarios pertinentes para cada uno de ellos.

${ }^{8}$ Esta obra fue reeditada en el año 1941, por el Instituto de Antropología de Tucumán bajo el título de Descripción corográfica del Gran Chaco Gualamba.

${ }^{9}$ Esta obra fue impresa por primera vez entre 1873-1875 por Andrés Lamas; no obstante en el año 2010 los miembros del Núcleo de Estudios Históricos Coloniales del Instituto de Investigaciones Geohistóricas-CONICET de Resistencia (Chaco, Argentina), lograron la edición de esta valiosa obra siguiendo detalladamente un manuscrito original de Pedro Lozano que se encuentra en el Archivo Nacional de Chile.
} 
- Además hallamos otras obras destacables como sus traducciones de los Ejercicios Espirituales de San Ignacio, los diccionarios históricos, y diferentes textos referidos al Tratado de Límites firmado entre la Corona Española y la Portuguesa hacia el año 1750.

Toda esta producción escrita, al igual que su vida, es recogida en una minuciosa investigación realizada por Furlong en su obra titulada Pedro Lozano S. J. y sus Observaciones a Vargas editada en 1959. El autor acopió los aportes más significativos de estudios anteriores, como los realizados por Andrés Lamas, Rómulo Carbia y Carlos Leonhardt. Se valió también de algunos datos de Francisco de Aparicio para analizar con precisión la vida y obra de este jesuita.

Una de las cuestiones que destaca Furlong es su metodología historiográfica, pues

«...maravilla, a la verdad, hallar en plena época colonial a un hombre que emprende y lleva a ejecución obras de tanto aliento...fue un investigador incansable que recorrió los archivos existentes en el país, copió y estudió cuantos documentos pudo hallar a mano, ordenó y encadenó los sucesos relatando causas y efectos y pronunció con la mayor imparcialidad el severo dictamen de la verdad objetiva e imparcial» ${ }^{10}$

Su trabajo con documentos recolectados en distintos archivos de la región, expone la agotadora labor de este padre y resalta su figura como historiador de la orden. Todo esto puede verse en las Cartas Anuas redactadas en el decenio 1720-1730. Sirvan de ejemplo los párrafos en los cuales aborda lo acaecido en la ciudad de Asunción durante la denominada Revolución de los Comuneros (1721-1735).

Ante los polémicos y conflictivos sucesos asuncenos hubo diferentes posturas. Muchas se manifestaron de forma escrita a través de epístolas. Lozano reproduce textualmente algunos fragmentos de las mismas, para que el lector de estas Anuas pueda comprender cuáles fueron los bandos enfrentados en Asunción y a quiénes apoyaban las personalidades e instituciones coloniales más importantes. Se leen así cartas de Diego de Morcillo, por entonces Virrey del Perú; de fray Pedro Fajardo, Obispo de Buenos Aires; de la Audiencia de la Plata y también del Cabildo de Asunción. Toda esta documentación, expuesta textualmente, permite observar la minuciosa tarea del autor de estas Anuas, cómo enriquece su relato y fundamenta su posición.

Señala Furlong que si bien en muchas oportunidades la tarea escrita de Lozano se nos presenta deficiente, manca e incompleta en algunas de sus partes,

\footnotetext{
${ }^{10}$ Furlong, Guillermo. 1993. Los Jesuitas y la Cultura Rioplatense: 46. Montevideo, Urta y Curbelo.
} 
en algunos de los hechos que narra y aún en algunos de los juicios que emite; sin embargo, examinando de manera conjunta su vasta obra, puede apreciarse su mucho valor y su importancia sin rival, pues muchísimos documentos a los cuales tuvo acceso, hoy en día se han extraviado, y tal vez para siempre. ${ }^{11}$

\section{COYUNTURA EN LA CUAL SE REALIZÓ ESTE DOCUMENTO}

La Compañía de Jesús inició su labor religiosa en los territorios rioplatenses hacia finales del siglo XVI, un poco más tarde si lo comparamos con el arribo a estas tierras de franciscanos, mercedarios y dominicos.

En esos años la Provincia Jesuítica del Perú, con sede provincial en la ciudad de Lima, se extendía desde lo que hoy día es Panamá hasta la actual provincia argentina de Tierra del Fuego. Esa excesiva extensión de tierras para administrar material y espiritualmente junto con la magnitud de los trabajos evangelizadores que pretendían realizar los jesuitas en la cuenca del Plata y los territorios aledaños, determinaron que el General de la Compañía Claudio Aquaviva ${ }^{12}$ decidiera la creación de la Provincia Jesuítica del Paraguay ${ }^{13}$ en el año 1604, designando al padre Diego de Torres Bollo como superior provincial.

Torres Bollo, acompañado de quince religiosos, llegó en el año 1607 a la ciudad de Córdoba (Argentina), sitio en el cual se estableció la cabecera de la jurisdicción y la sede del padre provincial.

Hubo un lento proceso de organización y consolidación. Sufrieron reveses como los ataques de las bandeiras paulistas que obligaron al traslado de algunos

\footnotetext{
${ }^{11}$ Furlong, Guillermo. 1959:.5.

${ }^{12}$ Se desempeñó como General de la Compañía de Jesús entre los años 1581 y 1615, por lo cual fue la autoridad que «dirigió» desde Roma los primeros pasos del accionar de esta orden en las regiones del Río de la Plata; véase por ejemplo las dos Instrucciones que dictó para los misioneros de la Compañía en los años 1603 y 1604; ambas publicadas íntegramente en Hernández, Pablo. 1913. Organización Social de las Doctrinas Guaraníes de la Compañía de Jesús, (vol. 1): 577-580. Barcelona, Gustavo Gili.

${ }^{13}$ Esta nueva provincia de la orden recibió el nombre de Paraguay, pero la misma abarcó un territorio mucho más extenso que el perteneciente al actual estado del Paraguay, comprendiendo territorios que hoy pertenecen a Argentina, Paraguay, Uruguay, un sector de Bolivia, el sur de Brasil y Chile. Este último territorio fue convertido en Vice-provincia de la orden, y por tanto separado de la Provincia Jesuítica del Paraguay, en el año 1635. Además recordemos que la gobernación del Paraguay fue dividida en 1617 en las gobernaciones de Buenos Aires (capital Buenos Aires) y del Paraguay (capital Asunción), división administrativa que tuvo su correlato con la creación de los Obispados con igual denominación en el año 1620, por tanto puede observarse las modificaciones en la administración civil y religiosa (tanto del clero secular como del regular) durante la primera mitad del siglo XVII
}

Hispania Sacra, LXV

131, enero-junio 2013, 139-159, ISSN: 0018-215-X, doi: 10.3989/hs.2013.005 
pueblos a zonas más seguras. ${ }^{14}$ La Compañía logró afianzarse en esta región hasta su supresión en el año 1767.

En la primera mitad del siglo XVIII, debemos decir que las Misiones Jesuíticas de guaraníes alcanzaron entonces el mayor grado de su desarrollo, estabilidad y expansión. Los llamados Treinta pueblos, ocho en territorio del Paraguay, quince en el de Argentina y siete en el Brasil, se consolidaron y contaban con una población considerable. ${ }^{15}$

\section{Mapa $\mathbf{N}^{\circ} 1$ \\ LOS TERRITORIOS OCUPADOS POR LAS REDUCCIONES DE LA COMPAÑÍA DE JESÚS EN EL NORDESTE RIOPLATENSE}

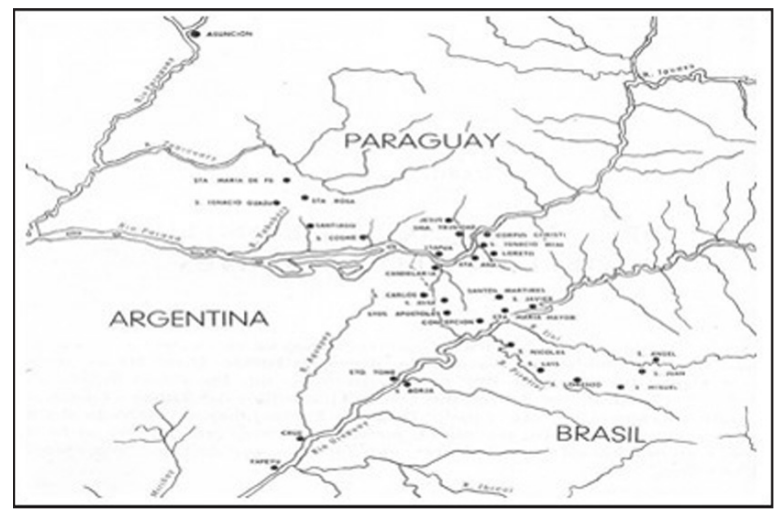

Fuente: Cayetano B. 1967. Historia de la Iglesia en la Argentina (1600-1632: 314). Buenos Aires: Don Bosco.

Desde el punto de vista demográfico, el decenio 1720-1730, se enmarca en los años previos al máximo apogeo de la población indígena «reducida»

${ }^{14}$ Las «bandeiras» o «malocas» paulistas produjeron graves consecuencias, se destruyeron las reducciones del Guayrá y apresaron a multitud de indios (objeto principal de los ataques), sólo se salvaron las reducciones de San Ignacio y de Loreto las cuales emprendieron el éxodo dirigidos sus habitantes por Antonio Ruiz de Montoya, hasta el nuevo emplazamiento en el Yabebiry; también las ciudades de Villa Rica y Ciudad Real debieron abandonar dicha región del Guayrá hacia 1632. Luego de la batalla de Mbororé (1641), en la cual los indios se enfrentaron a los portugueses, disminuyeron las amenazas de las «malocas», pero en ningún momento cesaron completamente estos ataques. Véase Maeder, Ernesto y Gutiérrez, Ramón. 1995. Atlas Histórico del Nordeste Argentino: 62-63. Resistencia: . Instituto de Investigaciones Geohistóricas (Conicet- Fundanord) Universidad Nacional del Nordeste.

${ }^{15}$ Maeder, Ernesto y Gutiérrez, Ramón. 1995:.66. 
ocurrida hacia 1732. En esta fecha se alcanzó en los pueblos la cifra aproximada de 141.182 indígenas reducidos. ${ }^{16}$

\section{ORIGEN Y FUNCIÓN DE ESTE TIPO DE DOCUMENTOS}

Ahora bien, para comprender el porqué o las causas de la redacción de éste y otros documentos semejantes, hay que centrarse en el origen y función que tuvieron los mismos dentro del funcionamiento interno de la Compañía de Jesús.

Hacia el año 1530, un estudiante de París llamado Iñigo López de Recalde conocido por la posteridad como San Ignacio de Loyola (1491-1556), había logrado congregar a un selecto grupo de jóvenes con quienes finalmente creó el 15 de agosto de 1534 en la capilla de Montmartre de París, a lo menos materialmente, la Compañía de Jesús. Seis años más tarde el papa Paulo IV aprobó la nueva orden religiosa, la cual se convirtió en una de las banderas de la Contrarreforma Católica en Europa, mientras que en América desempeñó una vital tarea de evangelización, adoctrinamiento y educación de la población indígena y criolla, especialmente en los territorios rioplatenses. ${ }^{17}$

San Ignacio de Loyola buscó conservar las características del primitivo grupo de amigos que se reúnen para servir mejor a su Señor y a sus hermanos. Para eso era necesario mantener un conocimiento mutuo entre los jesuitas, pese a estar alejados físicamente. Además el sistema de gobierno de la Compañía de Jesús tenía como base dos principios: el de obediencia ${ }^{18}$ y el de subordinación.

El primero «...delineaba, en efecto, una jerarquía de roles...en la cual el general era la cabeza de todo el sistema, seguido por los provinciales, los

${ }^{16} \mathrm{Cfr}$. Kleinpenning, Jan M. 2003. Paraguay 1515-1870. A Thematic Geography of its Development. (Volume 2): 1480. Madrid: Bibliotheca Ibero-Americana. Livi-Baci, Massimo and Maeder, Ernesto. 2004. «The Missions of Paraguay: the demography of an experiment: 200 Journal of Interdisciplinary History. Vol 35. Number 2.

${ }^{17}$ Véase Furlong, Guillermo.1962. Misiones y sus pueblos de guaraníes: 18. Buenos Aires: Balmes. Es numerosa la bibliografía que hace referencia a la Compañía de Jesús, su creación y las actividades desarrolladas por esta en el ámbito rioplatense, entre ellas podemos mencionar: Techo, Nicolás del. 1897. Historia de la provincia del Paraguay de la Compañía de Jesús. 5 v. Madrid. Ruiz de Montoya, Antonio. 1989. Conquista espiritual hecha por los religiosos de la Compañía de Jesús en las provincias de Paraguay, Paraná, Uruguay y Tape. (Rosario,); Lozano, Pedro. 1754. Historia de la Compañía de Jesús en la provincia del Paraguay. 2 v: Madrid. Mörner, Magnus. 1968. Actividades políticas y económicas de los jesuitas en el Río de la Plata: La era de los Habsburgos. Buenos Aires.

${ }^{18}$ A este principio se refiere San Ignacio en una de sus cartas más conocidas, la del año 1553. Véase Pavone, Sabina. 2007. Los jesuitas: desde los orígenes hasta la supresión: 21 Buenos Aires, Libros de la Araucaria 2007.

Hispania Sacra, LXV

131, enero-junio 2013, 139-159, ISSN: 0018-215-X, doi: 10.3989/hs.2013.005 
rectores de los colegios y los otros superiores locales». ${ }^{19}$ Con respecto al segundo, San Ignacio sostenía que «... era válido en todos los Estados bien regulados, así como en la jerarquía eclesiástica, y que sin él sólo podía reinar el caos». ${ }^{20}$

Todas estas características de la Compañía de Jesús hicieron que el Padre General tuviera que tener un conocimiento lo más completo posible de las situaciones y calamidades que afrontaban todos y cada uno de los sacerdotes de la orden, sin importar el lugar del mundo donde se encontraran. A partir de ese conocimiento, podría guiarlos y gobernarlos en el servicio de su Señor y de sus hermanos.

Por estos motivos comenzaron a redactarse informes epistolares regulares, conocidos como Cartas Anuas, para comunicarse el General residente en Roma $\mathrm{y}$ los jesuitas en distintas partes del mundo.

Existieron otras dos justificaciones. La primera, emplear las noticias, referidas a progresos y avances en la tarea evangelizadora y las dificultades en que muchos jesuitas vivían en lejanos territorios. Era como un instrumento para despertar el entusiasmo e interés en los jóvenes a fin de que participaran la acción evangelizadora de la Compañía de Jesús. La segunda, con esta información de las Cartas Anuas, se fomentaba que los amigos bienhechores de la Compañía mantuvieran su benevolencia y ayuda como partícipes de sus acciones en aquellos distantes territorios americanos. ${ }^{21}$

A estos informes, «Cartas Anuas», hay que datarlos como anuales sólo entre los años 1609 y 1617. Posteriormente fueron bianuales (1618-1619; 1626-1627; $1645-1646)$, trianuales (1632-1634; 1635-1637; 1637-1639; 1641-1643; 1647$1649 ; 1650-1652 ; 1652-1654)$. En el caso de las redactadas por el padre Lozano, corresponden a un periodo más extenso, el decenio 1720-1730. ${ }^{22}$ Por lo tanto, desde 1609 hasta 1762, no hubo una «regularidad anual» a pesar de lo que indica su nombre.

¿A qué se debió esta variabilidad en los años que abarcan estos informes? Fundamentalmente, a factores obligados como los constantes problemas en la administración de los jesuitas, tal como nos dice el Dr. Ernesto J. A. Maeder: «...

\footnotetext{
${ }^{19}$ Ibídem. 22.

${ }^{20}$ Ídem.

${ }^{21}$ Véase Cartas Anuas de la Provincia del Paraguay. 1637-1639, 1984. Advertencia de Ernesto J. A. Maeder. Introducción y notas de Hugo Storni S. J.: 15 Buenos Aires: FECIC.

${ }^{22}$ Es importante aclarar que hacemos referencias a los años de Cartas Anuas publicadas o próximas a publicarse, y no a aquellas cartas que aún se hallan inéditas actualmente.
} 
su redacción dependía del puntual envío del provincial de los informes particulares de cada colegio y de cada misión». ${ }^{23}$

Por lo tanto, debemos pensar en que cada padre de las reducciones y de los colegios de la Provincia debían enviar su informe puntualmente al Provincial, para que este a su vez aunara la información más importante en una sola carta, luego remitida al Prepósito General. Todo este proceso llevaba tiempo y estaba sometido a las vicisitudes de cada jesuita, ya sea en los colegios o en las reducciones. Eso causaba atrasos inevitables en la redacción de las Anuas.

La expansión a pueblos guaraníes marginales incrementaba las distancias y dificultaba una comunicación fluida con la Casa Provincial en Córdoba. Basta recordar que, a mediados del siglo XVIII, el viaje fluvial que unía a las ciudades de Asunción y de Santa Fe demoraba con buenas condiciones de navegación cuatro meses. ${ }^{24}$ Hay que deducir que era mayor el tiempo requerido para unir distancias semejantes por vía terrestre.

\section{LA FUENTE HISTÓRICA UTILIZADA: LA CARTA ANUA DEL DECENIO 1720-1730}

Estas son algunas particularidades del documento para su análisis y futura edición de la Carta Anua del periodo 1720-1730.

Se ha utilizado el manuscrito del padre Carlos Leonhardt, quien realizó la traducción al castellano de los originales en latín ubicados en el Archivo Nacional de Munich (Sección Jesuitas, fascículo $\mathrm{N}^{\circ} 283$ ). Este manuscrito de Leonhardt se encontraba en el Colegio Máximo de San Miguel, y luego se trasladó al Colegio del Salvador de la ciudad de Buenos Aires, donde se localiza actualmente. En este sitio el Dr. Ernesto J. A. Maeder, obtuvo la copia que gentilmente nos facilitó para el desarrollo de nuestra labor.

Con respecto al original en latín, consta de 57 fojas y se halla incompleto, por tanto carece de fecha y firma a diferencia de otras Anuas.

Ahora bien, la ausencia de la firma no implica que no sepamos quien realizó esta misiva. Carlos Leonhardt y Guillermo Furlong ${ }^{25}$ atribuyen esta Anua al padre Pedro Lozano. El segundo nos expresa claramente que este documento

\footnotetext{
${ }^{23}$ Cartas Anuas de la Provincia Jesuítica del Paraguay. 1644. 2000: 7. Resistencia: Instituto de Investigaciones Geohistóricas.

${ }^{24}$ Velázquez, Rafael Eladio. 1973. «Navegación Paraguaya en los siglos XVII y XVIII», Estudios Paraguayos. Vol. I. N 1: 64. Asunción: Universidad Católica Nuestra Señora de la Asunción.

${ }^{25}$ Ambos padres son jesuitas que han desarrollado diversas obras y minuciosas investigaciones referidas a la historia de la Compañía, es decir, son referentes eruditos en la materia para atribuir al padre Lozano esta Anua.
} 
posee «...todos los indicios, como el estilo y las peculiaridades de la técnica, de ser obra exclusivamente suya». ${ }^{26}$

Puede suponerse que esta Anua fuera firmada por quien ejercía el cargo de Provincial de la Provincia Jesuítica del Paraguay hacia esos años: Jerónimo de Herrán, quien ocupara dicho cargo entre los años 1729-1733, esto se deduce dado que la Carta Anua del período posterior (1730-1735), posiblemente elaborada por el padre Lozano, fue rubricada por el entonces Provincial Jaime de Aguilar (1733-1738). ${ }^{27}$

Pedro Lozano ejerció el cargo de Historiógrafo General de la Orden en estas tierras, pero la rubrica de las Anuas era una atribución del Provincial de la Compañía.

Esta Carta escrita por Lozano para 1720-1730 fue dirigida a Francisco Retz, ${ }^{28}$ General de la Compañía en Roma. ¿Por qué se nos presenta una Anua que abarcó un decenio? Esta situación no era habitual, ${ }^{29}$ a la cual responde Pedro Lozano al inicio de su escrito:

«...aunque bien merecía su redacción el celo de esta Provincia (refiere a las Anuas posteriores a las de 1720), sin embargo han sobrevenido tantos estorbos, de epidemias, de guerras, de crueles persecuciones contra toda esta Provincia, que apenas nos dejaron vivir, bastante ocupados con defender nuestra honra, en cuanto lo exigían las razones superiores de los intereses religiosos, así que no nos sobró tiempo para escribir cartas más prolijas». ${ }^{30}$

Al abarcar diez años, la información de esta Carta Anua busca ser concisa; destacando sólo aquellos acontecimientos más importantes en cada uno de los colegios y misiones de la orden en estas tierras, «...para no quitar a Vuestra

${ }^{26}$ Furlong, Guillermo.1959: 122.

${ }^{27}$ Ibídem: 122 y 126.

${ }^{28}$ Francisco Retz, bohemio, natural de Praga (1672-1750) actuó como padre General de la Compañía (1730-1750) «... dio un gran impulso a las misiones, establecidas en lo que es ahora Canadá y Estados Unidos, y estuvo muy lejos de olvidarse de los Guaraníes, si bien el nefasto Tratado de Límites, firmado por España y Portugal, le produjo días de zozobra y de amargura. Grave error fue de este General de la Compañía el haber elegido al Padre Lope Luis Altamirano, para actuar, en su nombre, en la cuestión de los Siete Pueblos que, por aquel tratado, quedaban bajo el pabellón lusitano.» Véase Furlong, Guillermo.1962: 618.

${ }^{29}$ Existen dos Cartas Anuas que abarcan un período mayor que diez años, exactamente once años, y son las de 1681-1692 y las de 1689-1700. Estas Anuas se hallan inéditas, aunque el autor Carlos A. Page ha publicado fragmentos de las mismas en su obra dedicada al colegio Máximo de Córdoba. Véase Page, Carlos A., 2004. El colegio Máximo de Córdoba (Argentina) según las Cartas Anuas de la Compañía de Jesús 1609-1767: 234-269. Documentos para la Historia de la Compañía de Jesús en Córdoba. Tomo I). Córdoba: B R Copias.

${ }^{30}$ CAPJP. 1720-1730.f. 1] 
Paternidad inútilmente el precioso tiempo invertido en el tan acertado gobierno de la universal Compañía». ${ }^{31}$

Las Cartas Anuas en general, poseen cierta estructura narrativa particular más allá de algunas variantes. Se observa esto en la correspondiente al decenio 1720-1730 redactada por el padre Lozano.

En primer lugar hay una visión general de la Provincia Jesuítica del Paraguay durante este período, al igual que lo hacen otras Anuas. Los datos más significativos son: el número de jesuitas incrementado en esos años, de doscientos cuarenta y seis a trescientos veinte individuos. Este hecho se debió al regreso de los padres procuradores de Europa con setenta y cuatro nuevos sacerdotes. Se establece además el número de miembros de la orden fallecidos, sesenta y seis, $\mathrm{y}$ el de admitidos durante dicho periodo, cuarenta y cinco. Se presenta una lista de los superiores ${ }^{32}$ y sus lugares de residencia, diez colegios, una casa de probación, un convictorio, y las treinta y nueve estaciones misionales. ${ }^{33}$

En segundo lugar, estas Anuas describen pormenorizadamente lo sucedido en territorios rioplatenses. En Cartas precedentes se expusieron también subdivisiones en su narración con los nombres de cada pueblo y/o con las expediciones a otras poblaciones indígenas no reducidas. En las Anuas de 1720-1730, Lozano emplea como estructura principal de su escrito, los diez colegios de la Provincia; mientras que engloba la situación de las distintas misiones bajo un sólo apartado titulado: «Las misiones de los Ríos Paraná, Paraguay y Uruguay». ${ }^{34}$

Menciona treinta y nueve estaciones misionales existentes, pero sólo hay referencia a treinta de ellas. Esto se debe al extravío de las restantes fojas de la Carta en las cuales posiblemente trató de la situación en esas reducciones ausentes, las establecidas entre los indios chiquitos, chiriguanos y lules. En las fojas que poseemos de esta sección, puede apreciarse cómo Lozano resalta principalmente los acontecimientos vinculados a la fe de los pobladores de algunos de los pueblos administrados por la Compañía de Jesús, y no brinda un detalle minucioso de lo sucedido en cada uno durante esos años, desde el punto de vista político-administrativo. ${ }^{35}$

${ }^{31}$ CAPJP. 1720-1730. f. 1.

${ }^{32}$ El padre Lozano expresa en este sentido: «Cuenta la Provincia ciento ochenta y cuatro sacerdotes; cincuenta y dos Hermanos escolares; siendo los demás hermanos coadjutores, empleados en los oficios domésticos y ocupaciones rurales.» CAPJP. 1720-1730.f. 1 vta.

${ }^{33}$ CAPJP. 1720-1730.f. 1 vta.

${ }^{34}$ CAPJP. 1720-1730.f. 51-f. 57vta.

${ }^{35}$ Aparecen diferentes casos ascéticos en las reducciones de Santa Rosa, Apóstoles, Santísima Trinidad, San José, Santo Tomé, San Ignacio Miní, Santos Mártires del Japón, Jesús, Anunciación de la Virgen o Encarnación. Véase CAPJP. 1720-1730.f. 52vta.; f. 53; f. 54; f. 54vta.; f. 55; f. 56vta.; f. 57. 
En cuanto a los colegios, en este escrito se remarcan los hechos que su autor consideró más significativos y lo hace en el siguiente orden: Córdoba, no sólo refiere a su colegio sino también al noviciado y al convictorio de dicha ciudad; Asunción, Santiago del Estero, San Miguel del Tucumán, Buenos Aires, Santa Fe, La Rioja, Salta, Corrientes y Tarija.

Expone algunos datos sobre el número de individuos de la orden que residen en cada colegio; cifras que sintetizamos en este cuadro:

\begin{tabular}{|l|c|c|c|c|c|c|c|c|}
\hline \multirow{2}{*}{$\begin{array}{c}\text { INSTITUCIÓN DE } \\
\text { LA COMPAŃIÍA DE }\end{array}$} & \multirow{2}{*}{$\begin{array}{c}\text { No RELÍS } \\
\text { JIOSOS }\end{array}$} & \multicolumn{2}{|c|}{ DIFERENCIACIÓN } & \multicolumn{5}{c|}{ FALLECIDOS } \\
\cline { 5 - 11 } & S. & H.E & H.C. & TOTAL & S. & H.E & H.C \\
\hline Colegio de Córdoba & 100 & 25 & - & - & 9 & 6 & 2 & 1 \\
\hline Noviciado de Córdoba & 18 & 5 & - & - & 1 & - & - & 1 \\
\hline Convictorio de Córdoba & 7 & 5 & - & 2 & 1 & - & - & 1 \\
\hline Colegio de Asunción & - & - & - & - & 5 & 2 & - & 3 \\
\hline $\begin{array}{l}\text { Colegio de Santiago del } \\
\text { Estero }\end{array}$ & - & - & - & - & 2 & 2 & - & - \\
\hline $\begin{array}{l}\text { Colegio de San Miguel } \\
\text { de Tucumán }\end{array}$ & 7 & 5 & 1 & 1 & 2 & 1 & - & 1 \\
\hline $\begin{array}{l}\text { Colegio de Buenos } \\
\text { Aires }\end{array}$ & 19 & 12 & - & 7 & 8 & 6 & 1 & 1 \\
\hline Colegio de Santa Fe & 8 & 6 & 1 & 1 & 2 & 1 & - & 1 \\
\hline Colegio de La Rioja & 9 & 6 & - & 3 & 2 & - & - & 2 \\
\hline Colegio de Salta & 11 & 8 & - & 3 & 3 & 2 & - & 1 \\
\hline Colegio de Corrientes & 8 & 6 & - & 2 & 2 & 1 & - & 1 \\
\hline Colegio de Tarija & 10 & 7 & - & 3 & 3 & 3 & - & - \\
\hline
\end{tabular}

Referencias: S.: Sacerdote; H.E.: Hermano Escolar; H.C.: Hermano Coadjutor Elaboración propia. Fuente: CAPJP1720-1730. f. 1vta.-f. 6; f. 15-f. 17; f. 23vta.; f. 27- f. 28vta.; f. 37 - f. 38 ; f. 41 ; f. 42 ; f. 43 ; f. 45 - f. 46.

Estas Cartas Anuas, como puede observarse en el cuadro precedente, no brindan cifras exactas de cada colegio; es decir, no hallamos precisión en el número de los sacerdotes, los hermanos escolares y los coadjutores. Sin embargo, brindan una mirada global de la dimensión de cada uno. El más importante fue el de Córdoba donde residían las autoridades provinciales de la orden. En esta ciudad no sólo hallamos un colegio sino también el noviciado y el convictorio, que en su conjunto poseían un gran número de jesuitas; ello demuestra la importancia de esta urbe para la Compañía de Jesús. 
En orden jerárquico descendente encontramos luego al colegio de la Asunción, el más antiguo. Sin embargo no se presenta una cifra del número de padres residentes, quizás ello se debe al contexto que vivía el colegio en esos años: la Revolución de los Comuneros (1721-1735), por la cual los jesuitas fueron expulsados de la ciudad.

Luego se nos presenta el colegio de Buenos Aires, con un número considerable de padres; lo cual remarca la creciente importancia de esta urbe hacia esos años.

En los restantes colegios (Corrientes, Salta, Santa fe, La Rioja, Tarija y Tucumán) hay una población de jesuitas que oscila entre los 7 y 11 individuos. Con respecto al colegio de Santiago del Estero en estas Anuas no se establece el número preciso de jesuitas que lo habitaban.

Estas cifras deben ser tomadas con suma precaución, pues la población de cada uno de estos colegios no fue constante a lo largo de los diez años. Las causas son diversas, entre ellas: defunciones; carácter temporal de algunos padres y misiones evangelizadoras que se emprendían desde los colegios a las regiones cercanas.

El padre Lozano describe las cualidades de cada de los fallecidos y sus virtudes: fe, humildad, perseverancia, sencillez y obediencia a sus superiores. En su relato aparecen como dignos ejemplos para los padres más jóvenes, pues una de las funciones importantes que tenían las Cartas Anuas en la formación de los nuevos jesuitas.

Como muestra, la necrológica del jesuita Lorenzo Rillo, ${ }^{36}$ quien «...siendo súbdito o superior, siempre procedía con tal virtud y santidad en todo, que era preciso tenerle por varón perfecto. Nadie le pudo sorprenderle jamás en la menor lesión de las reglas de la Compañía». ${ }^{37} \mathrm{La}$ de Felipe Suárez ${ }^{38}$ señala que, en su misión a los indios chiquitos cercanos al colegio de Tarija, logró que

\footnotetext{
${ }^{36}$ Lorenzo Rillo nació el 17 de marzo de 1676 en Villafeliche (Zaragoza, España). Ingresó a la Compañía el 16 de mayo de 1692 en Aragón. Llego a Buenos Aires el 24 de septiembre de 1698. Su cuarto voto lo profesó el 15 de agosto de 1711 en San Ignacio (Misiones, Paraguay), y fue Provincial del Paraguay (28.11.1727-2.6.1729). Falleció el 15 de noviembre de 1729 en Córdoba (Argentina). Storni, Hugo. 1980: 239.

${ }^{37}$ CAPJP. 1720-1730.f. 5 .

${ }^{38}$ Felipe Suárez nació el 9 de junio de 1663, Almagro (Ciudad Real, España). Ingresó a la Compañía el 24 de marzo de 1678 en Toledo. Sus primero votos los profesó el 25 de marzo de 1685. Llegó a Buenos Aires el 3 de mayo de 1680. Se ordenó como sacerdote en diciembre de 1688 con el obispo Azcona. Su cuarto voto lo profesó el 24 de junio de 1696, en su presentación de Chiriguanos, en Tarija (Bolivia). Se desempeñó como Superior de Chiquitos (1710-12). Falleció el 31 de agosto de 1727 en Tarija. Véase Storni, Hugo. 1980: 279.
} 
a su conversación familiar nadie pueda resistirse, aconsejando constantemente la frecuencia de los sacramentos, el horror de los vicios, y el amor a la virtud. ${ }^{39}$

Con respecto a Domingo Zípoli, que murió a principios de 1726, dice Lozano: «Era gran músico, como lo probó, entre otros argumentos, por la publicación impresa de una obra musical». ${ }^{40}$ A lo cual agrega, que se desempeñó como «... director de coro en la Casa Profesa Romana, y bien hubiera podido aspirar a más pero sacrificó todo para dedicarse a la conversión de indios. A este fin entró en Sevilla a la Compañía, y partió para el Paraguay.»

Sobre las misiones evangelizadoras, Lozano subraya que «...el celo apostólico de nuestros Padres no se puede contener en la estrechez de la ciudad.... ${ }^{41}$ Son constantes las misiones rurales, también llamadas campestres, que parten desde los colegios. En ellas «...los incansables operarios de la Compañía suplen la falta de párrocos...» ${ }^{42}$ y con ellas «... reforman... las costumbres, instruyen a los rudos, y adminístranles los sacramentos» ${ }^{43}$

En esta labor, emprendida anualmente por parte de todos los colegios de la Compañía, dos jesuitas recorrían el distrito correspondiente, al menos durante dos meses. Para tener una idea más cabal de estas misiones, expone el autor brasileño Pedro Ignacio Schmitz:

«Eles (los padres de la Compañía) levantavam um pobre toldo junto a uma estancia ou aldeia indígena, pregavam, instruíam, confessavam, oficiavam a eucaristía, batizavam as crianças, celebravam e regularizavam matrimonios, reconciliavam os desentendidos e inimigos, promoviam a justicia social, numa palavra davam a população do campo do possibilidade da prática religiosa...» $\gg^{44}$

Pedro Lozano resalta lo hecho por los misioneros de los colegios de La Rioja y de Córdoba, que predicaron «...las novecientas millas por todos lo lados». ${ }^{45}$ Del primero, los jesuitas asistían con mayor frecuencia y a pesar de la distancia, a la misión de Catamarca como se hizo en el año 1721 con el rector Lorenzo

\footnotetext{
${ }^{39}$ CAPJP. 1720-1730.f. 51.

${ }^{40}$ CAPJP. 1720-1730.f. 5vta. Cabe aclarar que a la obra a la cual hace referencia Lozano estaba según los bibliógrafos redactada en lengua italiana y se publicó en Roma durante el año 1716 con el siguiente título, que damos en castellano: «Principios o nociones para tocar con acierto el órgano y la trompa». Véase Guillermo, FURLONG, Los Jesuitas y...p. 81.

${ }^{41}$ CAPJP. 1720-1730.f. 11.

${ }^{42}$ CAPJP. 1720-1730.f. 14 vta.

${ }^{43}$ CAPJP. 1720-1730.f. 14 vta.

${ }^{44}$ Schmitz, Pedro Ignácio. 2004. «Atividades religiosas desenvolvidas pelos colégios da provincia do Paraguai», X Jornadas Internacionales sobre Misiones Jesuíticas: Educación y Evangelización. La experiencia de un mundo mejor: 75-79 Córdoba: Universidad Católica de Córdoba.

${ }^{45}$ CAPJP. 1720-1730.f. 14vta.
} 
Rillo, y luego en 1728 con el padre Antonio de Almoguera. ${ }^{46}$ Desde el colegio de Córdoba, y a pesar de la magnitud de las regiones cercanas; la constante y ardua tarea de sus sacerdotes permitió que las confesiones llegaran cada año a diez mil, y las comuniones a más de ocho mil. ${ }^{47}$

También son destacables las misiones evangelizadoras desde el colegio de Tarija. Por un año entero salían dos sacerdotes a recorrer todas las aldeas de la comarca, teniendo que «...caminar por lugares solitarios, por las cumbres de muy altas montañas, muchas veces a pie, y hasta «arrastrándose a cuatro pies», no habiendo a veces paso ni para mulas». ${ }^{48}$ El padre Lozano brinda una visión de algunas de las numerosas adversidades que afrontaron los miembros de la Compañía para difundir el evangelio y la palabra de Dios

Menciona esta Carta Anua también expediciones netamente de carácter militar durante este período, en las participaron algunos jesuitas. Estas acciones fueron organizadas desde la ciudad de Córdoba. La del año 1721 exploró el gran río Pilcomayo y en ella estuvo el padre Gabriel Patiño. ${ }^{49}$

En las posteriores realizadas durante tres años seguidos contra los abipones, tres jesuitas se desempeñaron como capellanes militares; encargándose de la tarea de predicar y confesar a los soldados de los demás ministerios, y que se portaran como buenos cristianos. Antes de iniciar su marcha se confesaron todos, realizaron sus prácticas piadosas en los campamentos y lograron desterrar por completo las blasfemias, juramentos, deshonestidades y otros vicios tan comunes entre ellos. ${ }^{50}$

El colegio de Santa Fe afrontó grandes dificultades en este período, de hecho estuvo a punto de arruinarse a causa de la guerra contra los abipones que asolaban la ciudad. Fue tan crítica la situación que «...apenas había allí de comer, por espacio de varios años; y nadie se atrevía a salir de la ciudad, por el peligro de perder la vida.» Incluso se trató de suprimir varias veces el colegio de la Compañía, pero para que los jesuitas no sean tachados de cobardes ha sido diferida esta resolución..$^{51}$

${ }^{46}$ CAPJP. 1720-1730.f. 42.

${ }^{47}$ CAPJP. 1720-1730.f. 11 vta.

${ }^{48}$ CAPJP. $1720-1730$. f. 47.

${ }^{49}$ CAPJP. 1720-1730. f. 4vta. Con respecto al padre Gabriel Patiño, debemos decir que nació el 1 de noviembre de 1662, en Asunción (Paraguay). Ingresó a la Compañía el 16 de junio de 1682 en Paraguay. Sus primeros votos los efectuó el 18 de junio de 1684, la ordenación sacerdotal la realizó el 26 de octubre de 1692, con el obispo Azcona; y sus cuartos votos los profesó el 15 de agosto de 1699, en Corrientes (Argentina). Falleció el 30 de junio de 1729 en Córdoba (Argentina). Véase Storni, Hugo. 1980:.214.

${ }^{50}$ CAPJP. 1720-1730.f. 13vta.f. 14.

${ }^{51}$ CAPJP. 1720-1730. f. 37vta. 
La ciudad no hubiera resistido más los ataques de estos indios sino hubieran sido enviadas, por propia iniciativa del Procurador General de las Misiones del Paraguay; tropas auxiliares de indios guaraníes para defender y fortificar la ciudad con fosas y palizadas. ${ }^{52}$

Sobre la tarea educativa de la Compañía, en la Universidad de Córdoba florecieron mucho durante este decenio los estudios literarios, pues «...que muchísimos han alcanzado el grado de Maestro en filosofía, y nada menos que veintiocho estudiantes, después de un examen riguroso, han sido graduados de Doctores.... ${ }^{53}$ Lo destacaba el obispo de Tucumán en una carta que Lozano cita y fecha el 20 de abril de 1729: «...bajo la sabia dirección de la Compañía florece... esta Universidad de Córdoba (...). En ella están a gran altura los estudios literarios, recibiendo los estudiantes más aptos los grados académicos. ${ }^{54}$

Por su parte, el colegio de Asunción, con graves problemas en los inicios de la Revolución Comunera, logró tras ellos abrir una Escuela de Primeras Letras y otra de Gramática, permitiendo el regreso de los antiguos discípulos que tuvieron que frecuentar «mal de su agrado», las escuelas de otras órdenes religiosas pues, como hemos visto, fueron expulsados de la ciudad los jesuitas. ${ }^{55}$

El colegio de Santiago del Estero esos años también vivió una situación adversa por las deudas que contrajo, pero finalmente superó ese momento e incrementó su biblioteca gracias a los tres mil seiscientos pesos que donó generosamente el Teniente de gobernador Alonso de Alfaro. ${ }^{56}$ Situación semejante experimentó el de Santa fe, gracias al legado testamentario de mil pesos de don Francisco de Piedrabuena, por el cual se adquirieron muchos libros e incluso algunos ejemplares traídos de España. ${ }^{57}$

Con todos estos datos se comprueba las diversas y dispares situaciones de cada colegio esos años. Se aprecia su labor evangelizadora, educativa y cultural, pese a las dificultades. Una de las más destacadas en el relato de Lozano son las pestes y epidemias en las regiones cercanas a los colegios de Córdoba, Buenos Aires, La Rioja, Santa Fe y Tarija. ${ }^{58}$

Además en la región cercana al colegio de Tarija estaba la amenaza constante de los portugueses, con sus incursiones desde Brasil para apoderarse de indios. Esos años los lusitanos causaron «...una gran calamidad a las vecinas misiones

\footnotetext{
${ }^{52}$ CAPJP. 1720-1730.f. 40vta.

${ }^{53}$ CAPJP. 1720-1730.f. 6vta.

${ }^{54}$ CAPJP. 1720-1730.f. 15.

${ }^{55}$ CAPJP. 1720-1730.f. 23vta.

${ }^{56}$ CAPJP. 1720-1730.f. 25.

${ }^{57}$ CAPJP. 1720-1730.f. 38.

${ }^{58}$ Véanse CAPJP. 1720-1730.f. 6; f. 15vta.; f. 32; f. 37vta.; f. 40vta.; f. 42vta.; y f. 46.
} 
de indios Chiquitos... ${ }^{59}$ Finalmente fueron rechazados tras una gran batalla, pero con consecuencias negativas para la Compañía, ya que:

«...cundió el pánico hasta entre los Chiriguanos, los cuales echaron en cara a los Padres la especie, de haberlos juntado en pueblo sólo con el fin de poder entregarlos con más facilidad a los Lusitanos. Llegó el alboroto a tal grado, que, llenada su cabeza por esta idea falsa, e instigados por algunos cristianos de mala ley, asaltaron la casa de los misioneros y su iglesia, y las quemaron. Escaparon con vida los dos misioneros Felipe Suárez y Lucas Caballero, y volviendo las espaldas a su ingrata misión de Chiriguanos, se marcharon a la más feliz de los indios Chiquitos.... ${ }^{60}$

En el colegio de Asunción durante la llamada Revolución de los comuneros, hubo dos momentos: uno de 1721-1724 y, tras un período de tensa paz, otro entre 1731-1735.

A la primera etapa se refiere la Carta Anua del decenio 1720-1730. La revolución fue dirigida por un grupo de encomenderos enfrentados con la Compañía a causa del papel que tenían en el mercado de la yerba y el control de la fuerza de trabajo de los indígenas de las reducciones. Hubo en la ciudad claros signos de disconformidad de una parte de la población, por la ilegal designación de Diego de los Reyes Balmaceda como gobernador; pues era vecino del pueblo que iba a gobernar, lo cual estaba prohibido.

La Audiencia de Charcas envió a José de Antequera y Castro, como juez pesquisidor. Este probó los cargos contra Reyes de Balmaceda, quien fue destituido; quedando el mismo Antequera como gobernador.

Los asuncenos esta vez con su gobernador a la cabeza, formularon una serie de cargos contra los miembros de la orden y se enfrentaron a ellos; logrando expulsarlos de la ciudad y su colegio. Los jesuitas recurrieron entonces al Virrey del Perú, quien colocó a Reyes de Balmaceda nuevamente en el cargo por un corto periodo; para luego reemplazarlo por Baltasar García Ros. Los habitantes de Asunción se levantaron contra esta medida arbitraria que desobedecía la disposición de la Audiencia de Charcas. El conflicto terminó de manera sangrienta con el enfrentamiento armado sobre el río Tebicuary. ${ }^{61}$ El ejército leal

\footnotetext{
${ }^{59}$ CAPJP. 1720-1730.f. 50 .

${ }^{60}$ CAPJP. 1720-1730.f. 50.

${ }^{61}$ «...los indios... se arrojaron al repaso del río donde se ahogaron los más que pasaron y murieron aquel día y fueron como 400 indios, sin haber tenido desgracia los españoles.» Aguirre, Francisco de. 2003. Discurso Histórico sobre el Paraguay: 433. Estudio Preliminar Ernesto J. A. Maeder. Buenos Aires, Union Académique Internationale-Academia Nacional de la Historia.
} 
a la Corona compuesto por milicias guaraníes,${ }^{62}$ fue derrotado en 1724 por los asuncenos.

Todos estos sucesos son descriptos por estas Anuas de manera minuciosa, aunque omitiendo la gran derrota de Tebicuary. Esto último refleja claramente la parcialidad del relato del padre Lozano. ${ }^{63}$

En estas Cartas Anuas también se expone una visión general de la situación de las Misiones de los ríos Paraná, Paraguay y Uruguay. No analizan los asuntos temporales pero aportan el número de jesuitas: 60 sacerdotes y 4 hermanos coadjutores. Observa Pedro Lozano en su relato que «... se eleva a 73 sujetos. Pero hay entre ellos tantos ancianos decrépitos, y enfermos imposibilitados, que sólo el número indicado de 60 está a disposición para faenas tan duras» ${ }^{64}$

En los treinta pueblos, según este autor, la población asciende a 132.685 almas, distribuidas en 29.100 familias cristianas; y añade Lozano «...la gran prosperidad de estos pueblos se puede comprender, tomando en cuenta, que en un solo año tuvieron un aumento de 7.000 cristianos». ${ }^{65}$ Cita luego numerosos ejemplos apologéticos de la fe cristiana, como ser la ayuda del Santo Padre Ignacio a sus fieles y los numerosos beneficios que conllevaba la práctica de los Ejercicios Espirituales.

\section{LA TAREA INCONCLUSA DE EDITAR ESTAS FUENTES HISTÓRICAS DE GRAN VALOR.}

En las primeras décadas del siglo xx se inició una tarea hasta hoy inconclusa, la de editar el corpus documental de Cartas Anuas comprendidas entre 1609 y 1762, o al menos las que aún se conservan.

Esta labor la inició el jesuita Carlos Leonhardt S. J. y el historiador Emilio Ravignani, quienes publicaron las primeras Cartas en 1927 y 1929 en dos volúmenes, titulados las «Cartas Anuas de la Provincia Jesuítica del Paraguay de la Compañía de Jesús» en los tomos XIX y XX de la Colección de Documentos para la Historia Argentina, publicación emprendida por el Instituto de Investigaciones Históricas de la Facultad de Filosofía y Letras de la Universidad de Buenos Aires.

${ }^{62}$ «Se creyó bastaban los indios misioneros para la empresa y juntando un ejército de 5.000 hombres llegó el señor Ros cerca del paso del Tebicuary al entrar agosto de 1724.» Aguirre, Francisco de. 2003: 431.

${ }^{63}$ CAPJP. 1720-1730.f. 17-f. 22vta.

${ }^{64}$ CAPJP1720-1730.f. 51vta.

${ }^{65}$ CAPJP1720-1730.f. 51 vta. 
En el tomo XIX se hallan siete Cartas Anuas que van desde el año 1610 hasta 1615; mientras que en el XX se presentan las cartas de 1616, 1617, 1618, 1620, las del cuatrienio 1632-1634 y las del trienio 1635-1637. Las Anuas de 1621 a 1627 y las de 1632 a 1634, debido a que se consideraban por entonces extraviadas, no pudieron ser editadas. ${ }^{66}$

La falta de recursos económicos y otros problemas impidieron continuar con esta tarea. La publicación de estas fuentes es continuada en el año 1979 por el Dr. Ernesto J. A. Maeder; quien logró editar aquellas pertenecientes a 16371639, realizando la edición y la Advertencia Preliminar, siendo enriquecida esta edición con una Introducción y notas de Hugo Storni.

A partir del año 1984, el Dr. Maeder es Director del Instituto de Investigaciones Geohistóricas (IIGHI-Conicet, Argentina), lugar desde el cual continuó esta importante tarea de edición de fuentes jesuíticas. En 1990 publicó las Anuas del trienio 1632-1634 con el apoyo de la Academia Nacional de la Historia.

Entre los años 1996 y 2000, se consiguió la edición de las Anuas sucesivas, es decir, pertenecientes a 1644 y las del trienio 1641-1643, respectivamente. En 2007 el Dr. Maeder, con la colaboración de la Dra. María Laura Salinas, editó las Anuas del bienio 1645-1646 y las trianuales de 1647-1649.

A partir del año 2008, la Dra. Salinas dirige la publicación, introducción y notas de las Cartas Anuas de los trienios 1650-1652 y 1652-1654 (2010) y las de 11658-1660 y 1659-1662 (2011), las cuales se suman a la analizada en este trabajo, las del periodo 1720-1730. Siendo esta última de gran valor, dado que podría constituirse en la primera Carta Anua de la Provincia Jesuítica del Paraguay del siglo XVIII en ser publicada. Este cuerpo documental de gran valor histórico, próximo a ser editado, permitirá ampliar los conocimientos acerca de la labor misional, cultural y religiosa de la Compañía de Jesús en estos territorios.

\section{BibILIOGRAFÍA}

Aguirre, Francisco de. 2003. Discurso Histórico sobre el Paraguay: Estudio Preliminar Ernesto J. A. Maeder. Buenos Aires, Union Académique InternationaleAcademia Nacional de la Historia.

Cartas Anuas de la Provincia del Paraguay. 1637-1639, 1984. Advertencia de Ernesto J. A. Maeder. Introducción y notas de Hugo Storni S. J.: 15 Buenos Aires: FECIC.

\footnotetext{
${ }^{66}$ Cartas Anuas de la Provincia del Paraguay. 1637-1639.., p. 8.
} 
Cartas Anuas de la Provincia Jesuítica del Paraguay. 1644. 2000: 7. Resistencia: Instituto de Investigaciones Geohistórica.

Furlong, Guillermo. 1959. Pedro Lozano S. J. y sus «Observaciones a Vargas» (1750): 11 Buenos Aires, Librería del Plata.

Furlong, Guillermo.1962. Misiones y sus pueblos de guaraníes: 18. Buenos Aires: Balmes.

Furlong, Guillermo. 1993. Los Jesuitas y la Cultura Rioplatense: 46. Montevideo: Urta y Curbelo.

Hernández, Pablo. 1913. Organización Social de las Doctrinas Guaraníes de la Compañía de Jesús, (vol. 1). Barcelona: Gustavo Gili.

Kleinpenning, Jan M. 2003. Paraguay 1515-1870. A Thematic Geography of its Development. (Volume 2): 1480. Madrid: Bibliotheca Ibero-Americana

Livi-Baci, Massimo and Maeder, Ernesto. 2004. «The Missions of Paraguay: the demography of an experiment», Journal of Interdisciplinary History. Vol 35. Number 2

Lozano, Pedro. 1754. Historia de la Compañía de Jesús en la provincia del Paraguay. 2 v: Madrid.

Maeder, Ernesto y Gutiérrez, Ramón. 1995. Atlas Histórico del Nordeste Argentino Resistencia Instituto de Investigaciones Geohistóricas (Conicet- Fundanord) Universidad Nacional del Nordeste.

Mörner, Magnus. 1968. Actividades políticas y económicas de los jesuitas en el Río de la Plata: La era de los Habsburgos. Buenos Aires.

Pavone, Sabina. 2007. Los jesuitas: desde los orígenes hasta la supresión. Buenos Aires, Libros de la Araucaria.

Ruiz de Montoya, Antonio. 1989. Conquista espiritual hecha por los religiosos de la Compañía de Jesús en las provincias de Paraguay, Paraná, Uruguay y Tape. Rosario,

Schmitz, Pedro Ignácio. 2004. «Atividades religiosas desenvolvidas pelos colégios da provincia do Paraguai», X Jornadas Internacionales sobre Misiones Jesuíticas: Educación y Evangelización. La experiencia de un mundo mejor: Córdoba: Universidad Católica de Córdoba.

Storni, Hugo. 1980. Catálogo de los jesuitas de la provincia del Paraguay (Cuenca del Plata) 1585-1768: 167. Roma: Institutum Historicum S. I.

Techo, Nicolás del. 1897. Historia de la provincia del Paraguay de la Compañía de Jesús. 5 v. Madrid.

Velázquez, Rafael Eladio. 1973. «Navegación Paraguaya en los siglos XVII y XVIII», Estudios Paraguayos. Vol. I. N ${ }^{\circ}$ 1: 64. Asunción: Universidad Católica Nuestra Señora de la Asunción 